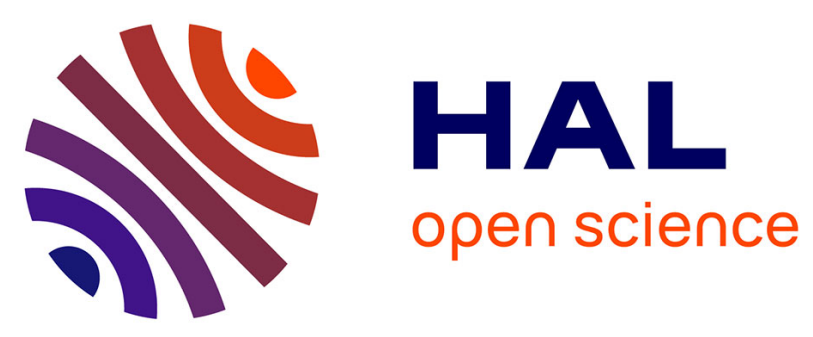

\title{
Plasmonic Enhancement by a Continuous Gold Underlayer: Application to SERS Sensing
}

Jean-François Bryche, Raymond Gillibert, Grégory Barbillon, Philippe Gogol,

Julien Moreau, Marc Lamy de La Chapelle, Bernard Bartenlian, Michael

Canva

\section{To cite this version:}

Jean-François Bryche, Raymond Gillibert, Grégory Barbillon, Philippe Gogol, Julien Moreau, et al.. Plasmonic Enhancement by a Continuous Gold Underlayer: Application to SERS Sensing. Plasmonics, 2016, 11 (2), pp.601-608. 10.1007/s11468-015-0088-y · hal-01230269

HAL Id: hal-01230269

https://hal-iogs.archives-ouvertes.fr/hal-01230269

Submitted on 5 Oct 2017

HAL is a multi-disciplinary open access archive for the deposit and dissemination of scientific research documents, whether they are published or not. The documents may come from teaching and research institutions in France or abroad, or from public or private research centers.
L'archive ouverte pluridisciplinaire HAL, est destinée au dépôt et à la diffusion de documents scientifiques de niveau recherche, publiés ou non, émanant des établissements d'enseignement et de recherche français ou étrangers, des laboratoires publics ou privés. 


\title{
Plasmonic enhancement by a continuous gold
}

\section{underlayer: application to SERS sensing}

\author{
Jean-François Bryche ${ }^{*, 1,2}$, Raymond Gillibert ${ }^{2,3,4}$, Grégory Barbillon ${ }^{1}$, Philippe Gogol ${ }^{1}$, Julien \\ Moreau $^{2}$, Marc Lamy de la Chapelle ${ }^{3}$,Bernard Bartenlian ${ }^{1}$ and Michael Canva ${ }^{2,5}$ \\ 1 - Institut d'Électronique Fondamentale, CNRS, Univ Paris Sud, Université Paris-Saclay, \\ Bâtiment 220, rue André Ampère, 91405 Orsay Cedex, France.
}

2 - Laboratoire Charles Fabry (LCF), CNRS, Institut d'Optique Graduate School, Université Paris-Saclay,

2 Avenue Augustin Fresnel, 91127 Palaiseau Cedex, France.

3 - Laboratoire CSPBAT,

Université de Paris 13, Sorbonne Paris Cité, CNRS,

74 Rue Marcel-Cachin, F-93017 Bobigny, France.

4 - HORIBA Jobin Yvon,

Avenue de la Vauve, Passage Jobin Yvon, CS 45002-91120 Palaiseau, France.

5. Laboratoire Nanotechnologie Nanosystème, LN2 UMI CNRS 3463, 3IT, Université de Sherbrooke, Sherbrooke, QC, Canada 


\begin{abstract}
In this paper, we report on an improved enhancement of the SERS effect. Such improvement is obtained by using a continuous gold film (underlayer), which is added below an array of gold nanostructures. Two types of nanostructures were studied to validate our results: regular disk arrays with two diameters $(110$ and $210 \mathrm{~nm})$ and lines with a width of $110 \mathrm{~nm}$, all on a gold film of $30 \mathrm{~nm}$ thick. A supplementary gain of one order of magnitude on the SERS Enhancement Factor (EF) was experimentally demonstrated for several excitation wavelengths: 633, 660 and $785 \mathrm{~nm}$. With such SERS substrates, EFs of $10^{7}$ are observed for thiophenol detection. This opens the way towards routine and reliable detection of molecules at low concentration.
\end{abstract}

KEYWORDS: Plasmonics, SERS, Biosensors, Nanostructuration, Localized Surface Plasmon Resonance.

\title{
1. INTRODUCTION
}

Although the Raman Effect has been known since 1928[1], the weak intensity of the Raman signal was a disadvantage and has restricted its utilization to solid materials or to highly concentrated solutions. This disadvantage has been overcome by the discovery of SurfaceEnhanced Raman Scattering (SERS) spectroscopy by Fleischmann[2] in 1974, with the first observations of the Raman spectra of pyridine on roughened silver. This technique allows a significant enhancement of the Raman signal due to the exploitation of the plasmonic properties of 
metallic nanostructures. Since the SERS has paved the way to the single molecule sensitivity[3], the interest for SERS has grown exponentially[4].

Nowadays, SERS is a well-known versatile technique used to detect and identify chemical and biological species [5,6]. The surface roughness[7] of films or nanoparticles[8,9]/nanostructures[10] is a key point to enhance the electromagnetic field[11] for SERS measurements. High confinement of electromagnetic fields can be associated with the optical properties of metallic nanostructures as the localized surface plasmon resonances[11]. However, surface roughness is hard to control and it is most desirable for SERS applications to have reproducible and robust signals. Therefore, nanoscience and nanotechnology have been extensively used in recent years for SERS applications[11-13], especially nanofabrication[14] using techniques such as Electron Beam Lithography[11,12,15-17], Focused Ion Beam[11,18], Nanoimprint Lithography (soft[11,19-21] and hard[15]), Nanosphere Lithography[11,20,22]. With these nanostructured samples, SERS now cover fields like biosensing[4], electrochemical and environmental analysis[14] and new multitechniques[13] such as Femtosecond Stimulated Raman spectroscopy (FSRS)[23] or Tip-enhanced Raman spectroscopy (TERS)[24].

The influence of the nanostructure geometry and as a consequence of their optical properties on the SERS signal was intensively studied for nanostructure on $\operatorname{Si}[4,14,17]$ but less on glass[25] substrate or metallic layer. Some comparisons between flat gold and nanostructures on a gold layer on $\mathrm{Si}[26]$ are reported. In other field of studies, some comparisons between properties of square nanoparticles on a glass substrate[27] and on a gold film layer[28] were done with an investigation of field-enhancement effects in regular arrays by using two photon luminescence microscopy[29]. 
Due to its strong resonance peak in the visible range, its chemical stability in air, and its biocompatibility, the gold is used for our experiments.

Here, we report on a systematic way to improve sensitivity of SERS based on an array of gold nanostructures. By the addition of a gold thin layer $(30 \mathrm{~nm})$ under the array, we show a significant enhancement factor of the SERS signal of thiophenol deposited on the sample. The gold underlayer adds no complex step on the manufacturing process and even eases the realization of samples as well as their robustness. Measurements are done for three excitation wavelengths $(633 \mathrm{~nm}, 660 \mathrm{~nm}$ and $785 \mathrm{~nm}$ ), two geometries of nanostructures (disks and lines), two types of samples (on gold and on glass) and several periods and diameters.

\section{EXPERIMENTAL SECTION}

\subsection{Fabrication of gold nanostructures on gold underlayer and on glass substrate.}

First, the D263 Thin Borosilicate Glass substrate is cleaned with the following protocol: ethanol, acetone and Piranha solution (3:1 concentrated sulfuric acid to $30 \%$ hydrogen peroxide solution). Next, a thin gold layer of $30 \mathrm{~nm}\left(\mathrm{~h}_{1}\right)$ is deposited by e-beam evaporation on the substrate. A $2 \mathrm{~nm}$ thick Titanium layer is used as adhesion layer between gold and glass. A $80 \mathrm{~nm}$ layer of polymethylmethacrylate A2 (PMMA A2) was spin-coated on the substrate, and then exposed to the electron beam. Several $400 \times 400 \mu m^{2}$ areas with gold nanodisks or line arrays were fabricated by Electron Beam Lithography (NanoBeam). A step of development in 1:3 methylisobutylketone / isopropanol (MIBK/IPA) solution is used to reveal nanostructures. Next, a $30 \mathrm{~nm}$ gold film is evaporated on the sample. Finally, nanostructures were obtained after a lift-off process in acetone. The samples obtained are called Gold Nanostructures (GN) (disks or lines) on a Gold Underlayer 
(GU) so GNGU (Figures 1(a), 1(c) and 1(e)). For the fabrication of gold nanostructures on glass substrate, the same process is used without the evaporation of the gold underlayer, and the samples are simply called Gold Nanostructures (GN) (Figure 1(b), 1(d) and 1(f)). Due to the absence of a conductive layer under the resist and the insulating nature of the glass substrate, we added a thin layer of conductive polymer (Espacer 300Z, thickness around $20 \mathrm{~nm}$ ) on the top of the resist deposited by spin-coating before the e-beam lithography step in order to avoid charge effects[30,31]. Then, before the development step, this conductive thin layer is removed by deionized water during $1 \mathrm{~min}$. Other techniques to avoid charges effects are to monitor experimental parameters (current and electron energy) or to use a sacrificial layer[32]. Geometrical parameters of nanostructures are a height of $30 \mathrm{~nm}\left(\mathrm{~h}_{2}\right)$, diameters (D) of $110 \mathrm{~nm}$ for disks with periods (P) of 200, 250, $300 \mathrm{~nm}$ and $210 \mathrm{~nm}$ for 300,350 and $400 \mathrm{~nm}$. Lines with a width of $110 \mathrm{~nm}$ are also studied for two periods (400 and $500 \mathrm{~nm}$ ). 
a)

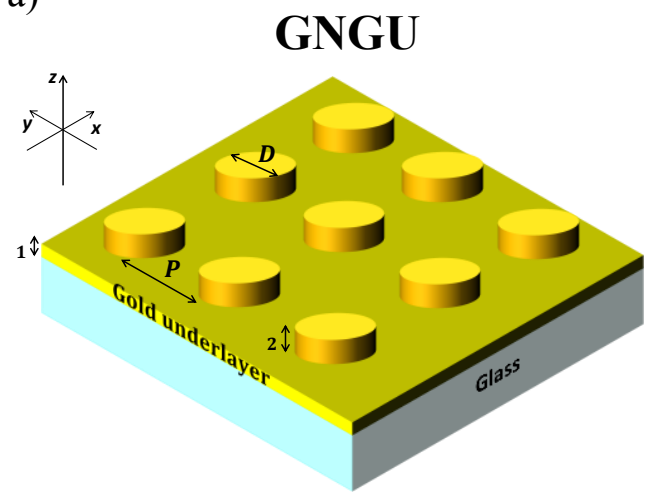

c)

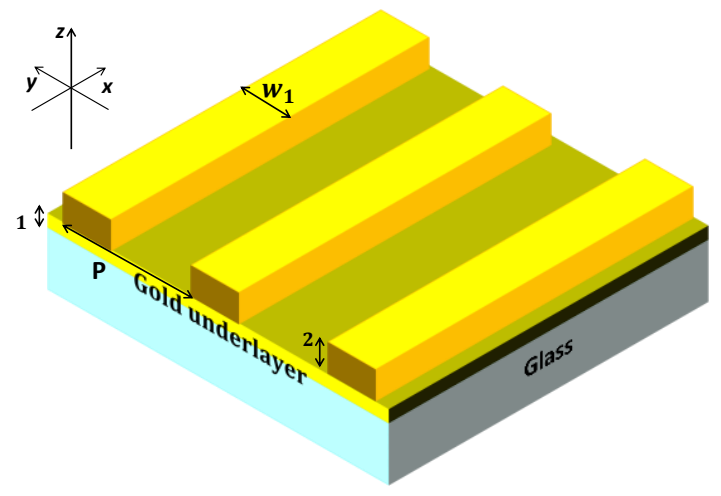

e)

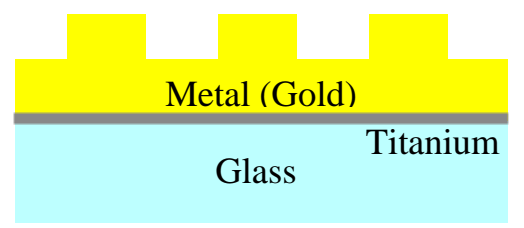

b)

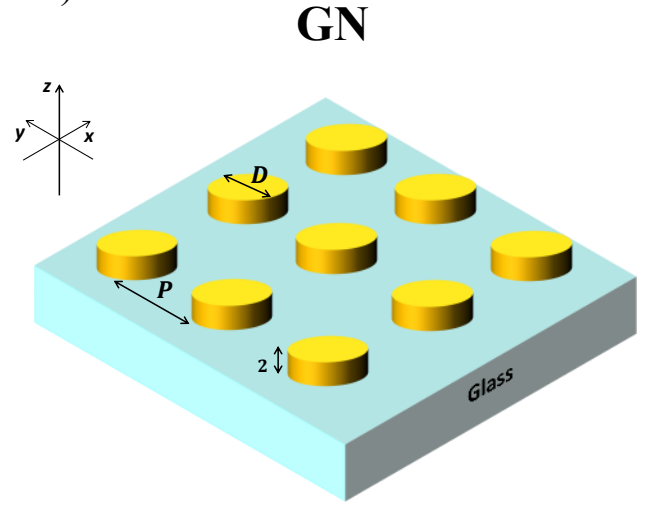

d)

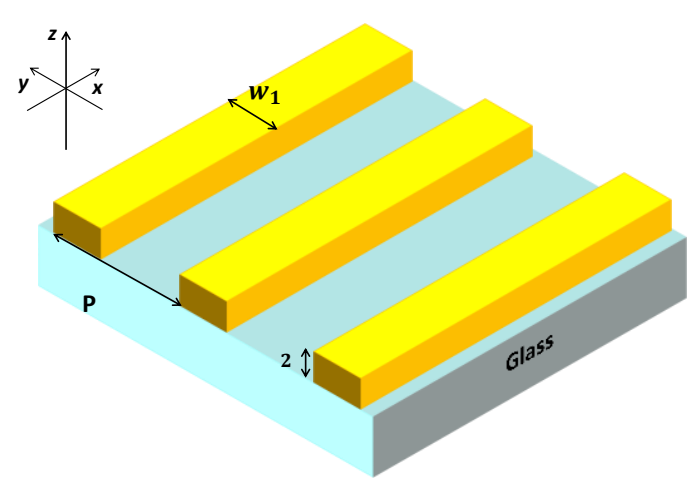

f)

Figure 1. (Top) Schematic representations of the samples used for SERS detection. Samples are made of an array of gold nanodisks (a) or lines (c) on a gold underlayer (GNGU) or gold nanodisks (b) or lines (d) on a glass substrate (GN). (Bottom) Schematic cross section views for GNGU (e) and $G N(f)$.

Nanostructure dimensions were measured by Scanning Electron Microscopy (SEM, SEMFEG Philips) (Figure 2) and confirmed by Atomic Force Microscopy (AFM). Thicknesses of the 
different layers, were obtained by ellipsometry (Ellipsometry-spectroscopy WOOLLAM) and Xray (Xpert MRD Philips).

a)

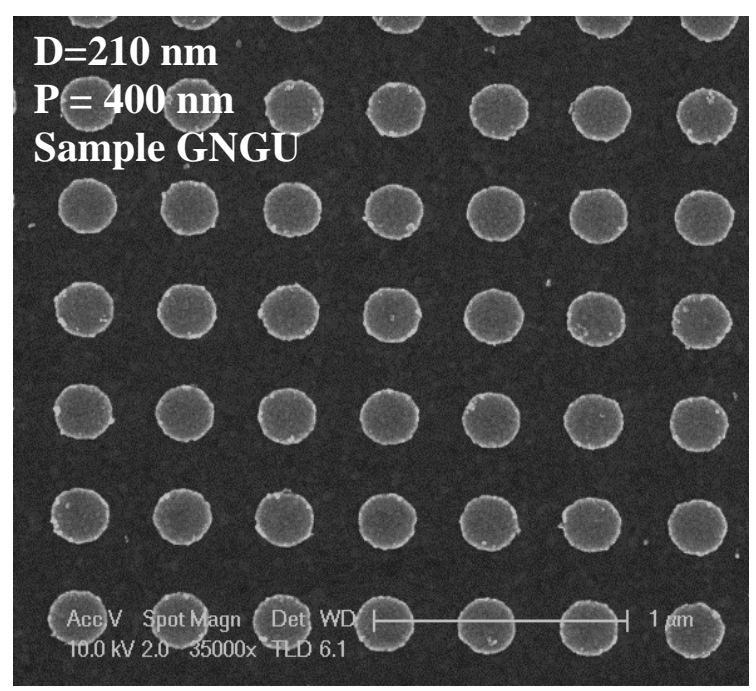

c)

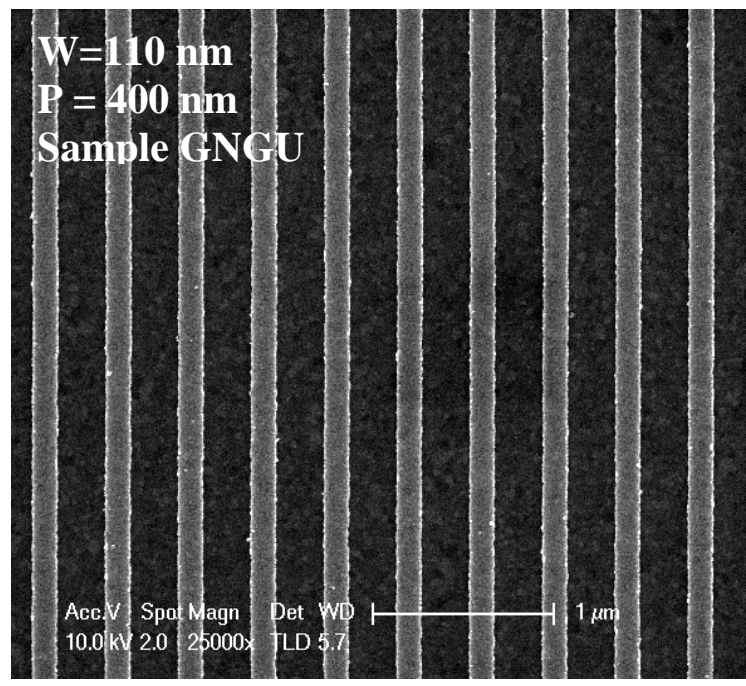

b)

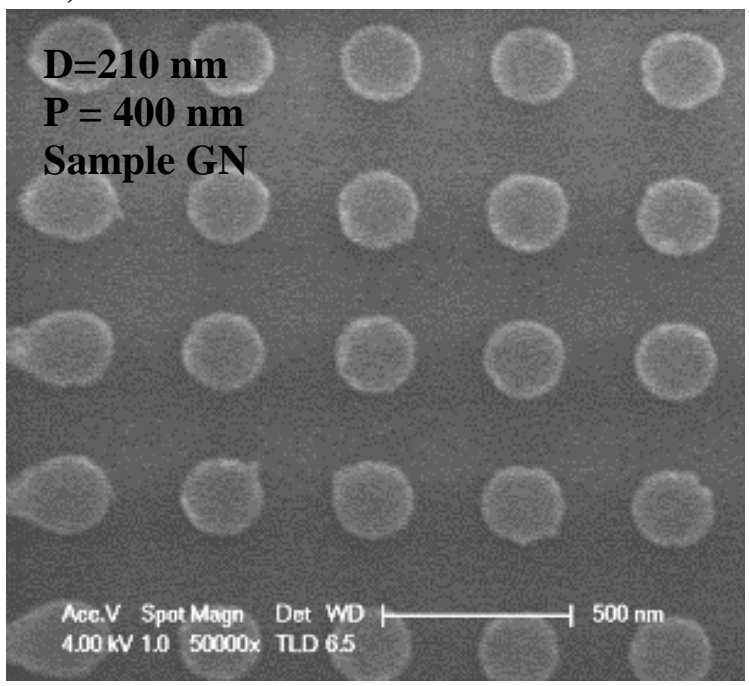

d)

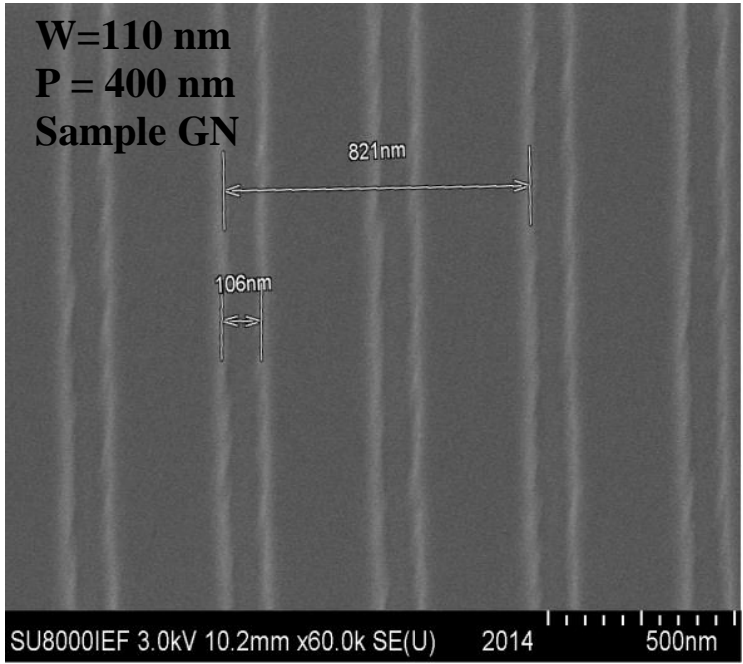

Figure 2. SEM pictures of gold disks (a) and lines (c) for GNGU, and disks (b) and lines (d) for $G N$. 


\subsection{Deposition of the thiophenol.}

Samples are immersed in a $0.1 \mathrm{mM}$ solution of Thiophenol $\left(\mathrm{C}_{6} \mathrm{H}_{6} \mathrm{~S}\right)$ for $2.5 \mathrm{~h}$ to have a saturation of the gold surface, then rinsed with ethanol for five minutes and dried up with Nitrogen. Thiophenol is frequently used as a probe molecule for SERS studies as it grafts on metal surface like other alkanethiols leading to a self-assembled monolayer. In addition, the thiophenol concentration used for the Raman experiment in solution is $1 \mathrm{M}$.

\subsection{Optical characterization.}

SERS measurements were performed using a Xplora spectrophotometer from Horiba Scientific with a microscope objective $(x 100$, N.A. $=0.9)$. Measurements were carried out in air using 633, 660 and $785 \mathrm{~nm}$ incident laser wavelengths. Characteristic Raman modes of thiophenol are observable at: $419 \mathrm{~cm}^{-1} / 1000 \mathrm{~cm}^{-1}$ (out of plane C-C-C stretch), $1025 \mathrm{~cm}^{-1}$ (out of plane C-H stretching), $1075 \mathrm{~cm}^{-1}$ (C-C-C stretch in plane and C-S stretching) and $1575 \mathrm{~cm}^{-1}$ (C-C stretching). The same acquisition protocol was used for GNGU and GN samples. In our experiments, SERS signals were obtained and averaged on several zones of the sample. In addition, for classical Raman measurements in solution, a macro-objective with a focal length of $40 \mathrm{~mm}($ N.A. $=0.18)$ and the three excitation wavelengths previously cited were used. All data have been normalized by the laser power and the acquisition time to be able to compare them. 


\section{RESULTS AND DISCUSSION}

\subsection{Influence of the gold film on the SERS signal.}

We demonstrate the influence of the continuous gold underlayer by reporting the SERS intensity of a periodic array of gold nanodisks (Figure 3) and nanolines (Figure 4) for an excitation wavelength of $660 \mathrm{~nm}$ for both type of substrates. For reference, no characteristic Raman peak is detected on a flat gold or a flat glass substrate (Figures 3 and 4).

It is clear from these results that the average SERS intensity of the GNGU samples is significantly higher than for GN samples, for the same acquisition time and the same laser power. Quantitatively, we defined the following ratio: $I_{G N G U} / I_{G N}$ where $I_{G N G U}$ is the peak intensity for GNGU sample and $I_{G N}$ for the GN sample. The characteristic peaks of Raman signal on the nanodisks are increased by a factor between 5 to 13 for GNGU sample compared to GN sample (Figure 3) and by a factor 2 to 6 for lines (Figure 4) depending on the Raman modes (See Table 1 for the $1575 \mathrm{~cm}^{-1}$ peak for all geometries). These results demonstrate the interest of using a continuous gold layer under a nanostructured sample to enhance the SERS signals, with a relatively low impact on the fabrication process. In addition, this gain between GNGU and GN cannot be explained by the increasing of overall gold surfaces, which would be linked to the number of excited molecules. Indeed, on flat gold, we have no signal of thiophenol and only those bonded to the nanostructures contribute to the detection (Figures 3 and 4). 


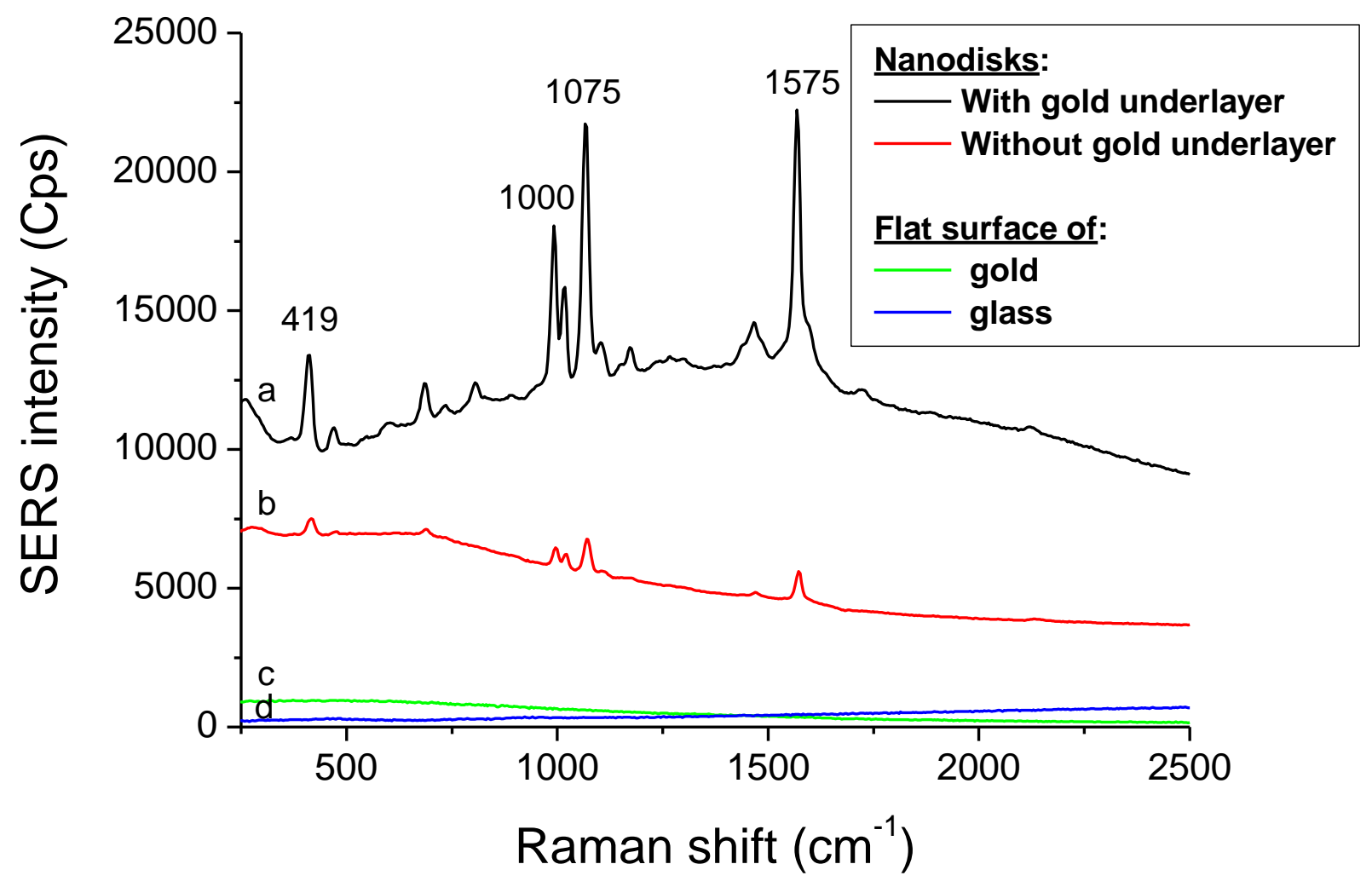

Figure 3. SERS intensity of thiophenol for an array of nanodisks with a diameter of $210 \mathrm{~nm}$ and a period of $400 \mathrm{~nm}$ on gold (GNGU) (a) and on glass (GN) (b), for a flat surfaces of gold (c) and glass (d). 


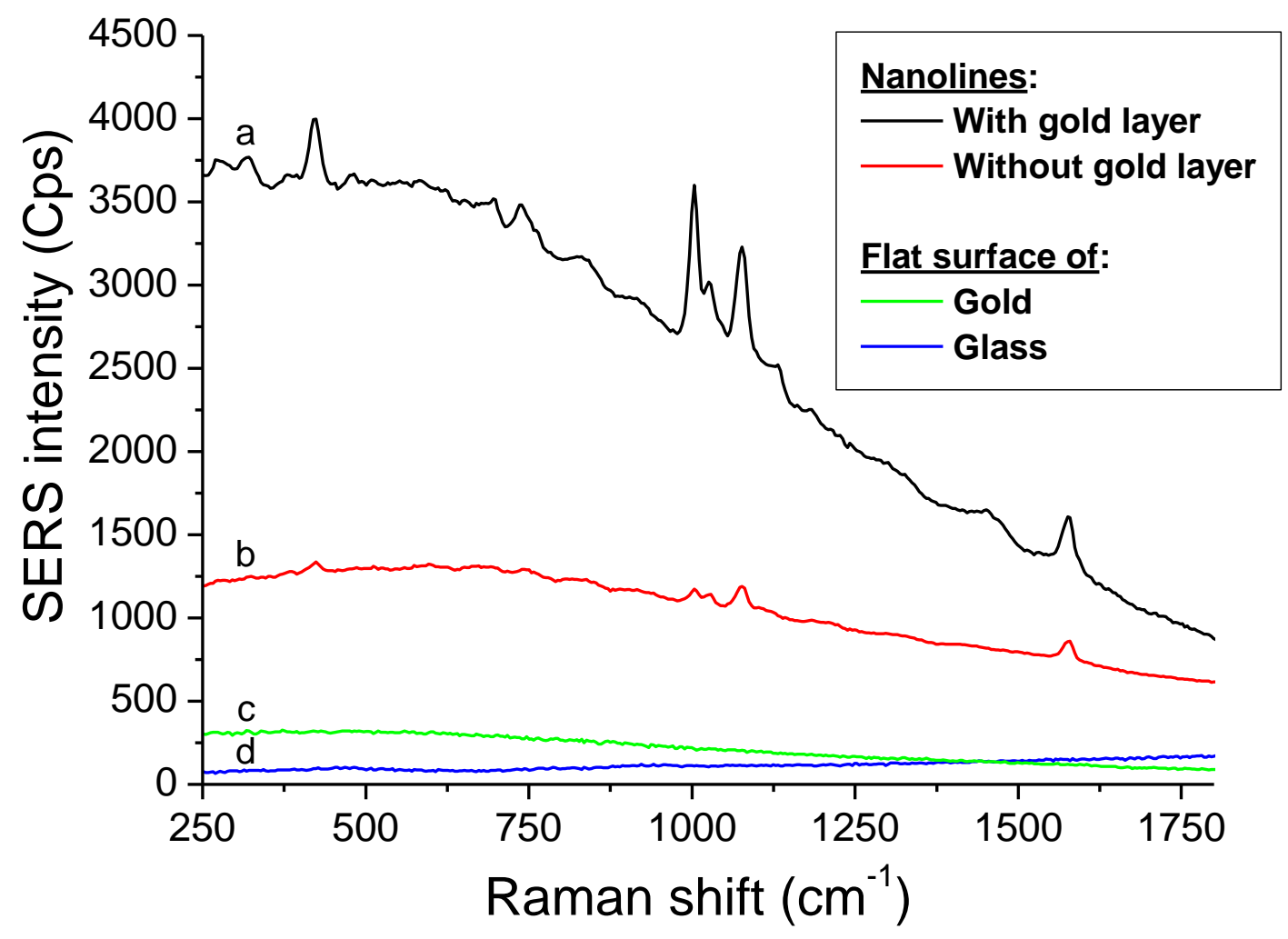

Figure 4. SERS intensity as function of Raman shift for a periodic array of lines with a width of $110 \mathrm{~nm}$, and a period of $400 \mathrm{~nm}$ on gold (GNGU) (a), on glass (GN) (b), and for a flat surfaces of gold (c) and glass (d).

We find similar behaviors (see Table 1 and supplementary data: Figures S1, S2, S3) for nanodisks with diameters of $110 \mathrm{~nm}$ and three different periods $(300 / 250 / 200 \mathrm{~nm})$ and also for lines with a width of $110 \mathrm{~nm}$ and a period of $500 \mathrm{~nm}$. Note that, the reflectivity of the substrate has a role in SERS measurements. From the paper of Zhao et al. [33], the SERS intensity increases linearly with 
the metallic underlayer reflectivity. Our SERS intensities and the reflectivity of gold and glass substrates used in our experiments are in good agreement with their studies.

Table 1: Integrated peak $\left(1575 \mathrm{~cm}^{-1}\right)$ ratio versus disk or line dimensions for three excitation wavelengths.

\begin{tabular}{|c|c|c|c|}
\hline $\begin{array}{l}\text { Disk dimensions } \\
\text { (diameter-period) }\end{array}$ & $\begin{array}{c}\text { Integrated peak ratio } \\
\left(\text { at } 1575 \mathrm{~cm}^{-1}\right) \\
I_{G N G U} / I_{G N}\end{array}$ & $\begin{array}{l}\text { Disk dimensions } \\
\text { (diameter-period) }\end{array}$ & $\begin{array}{c}\text { Integrated peak ratio } \\
\left(\text { at } 1575 \mathrm{~cm}^{-1}\right) \\
I_{G N G U} / I_{G N}\end{array}$ \\
\hline $110-200 \mathrm{~nm}$ & $\begin{array}{l}2.9 \text { at } 633 \mathrm{~nm} \\
6.2 \text { at } 660 \mathrm{~nm} \\
24.3 \text { at } 785 \mathrm{~nm}\end{array}$ & $210-300 \mathrm{~nm}$ & $\begin{array}{l}5.9 \text { at } 633 \mathrm{~nm} \\
10 \text { at } 660 \mathrm{~nm} \\
23.8 \text { at } 785 \mathrm{~nm}\end{array}$ \\
\hline $110-250 \mathrm{~nm}$ & $\begin{array}{l}2.6 \text { at } 633 \mathrm{~nm} \\
5.3 \text { at } 660 \mathrm{~nm} \\
16.2 \text { at } 785 \mathrm{~nm}\end{array}$ & $210-350 \mathrm{~nm}$ & $\begin{array}{l}6.9 \text { at } 633 \mathrm{~nm} \\
13.5 \text { at } 660 \mathrm{~nm} \\
19.2 \text { at } 785 \mathrm{~nm}\end{array}$ \\
\hline $110-300 \mathrm{~nm}$ & $\begin{array}{l}2.8 \text { at } 633 \mathrm{~nm} \\
5.9 \text { at } 660 \mathrm{~nm} \\
15.9 \text { at } 785 \mathrm{~nm}\end{array}$ & $210-400 \mathrm{~nm}$ & $\begin{array}{l}12.4 \text { at } 633 \mathrm{~nm} \\
9.9 \text { at } 660 \mathrm{~nm} \\
10.2 \text { at } 785 \mathrm{~nm}\end{array}$ \\
\hline $\begin{array}{l}\text { Line dimensions } \\
\text { (width-period) }\end{array}$ & $\begin{array}{c}\text { Integrated peak ratio } \\
\left(\text { at } 1575 \mathrm{~cm}^{-1}\right) \\
I_{G N G U} / I_{G N}\end{array}$ & & \\
\hline $110-400 \mathrm{~nm}$ & $\begin{array}{l}3.3 \text { at } 633 \mathrm{~nm} \\
2.7 \text { at } 660 \mathrm{~nm}\end{array}$ & & \\
\hline $110-500 \mathrm{~nm}$ & $\begin{array}{l}3.5 \text { at } 633 \mathrm{~nm} \\
1.2 \text { at } 660 \mathrm{~nm}\end{array}$ & & \\
\hline
\end{tabular}

For excitation wavelengths at $633 \mathrm{~nm}$ and $785 \mathrm{~nm}$, a similar behavior is found between the different samples. For an excitation of $633 \mathrm{~nm}$, ratios were measured between 7 and 13.1 for the 
four characteristics peaks of thiophenol $\left(419 \mathrm{~cm}^{-1}, 1000 \mathrm{~cm}^{-1}, 1075 \mathrm{~cm}^{-1}\right.$ and $\left.1575 \mathrm{~cm}^{-1}\right)$. For 785 $\mathrm{nm}$, values are between 8.4 and 15 . If we consider only the $1575 \mathrm{~cm}^{-1}$ Raman peak, for all excitation wavelengths $(633 \mathrm{~nm}, 660 \mathrm{~nm}$ and $785 \mathrm{~nm})$, a gain of one order of magnitude on the ratio is observed with the disks GNGU samples.

\subsection{Quantification of Enhancement Factor and discussion.}

The Enhancement Factor (EF) is defined by:

$$
E F=I_{S E R S} N_{\text {Raman }} / /_{\text {Raman }} N_{\text {SERS }}
$$

where $I_{S E R S}$ and $I_{\text {Raman }}$ are, respectively, the Raman intensities for thiophenol adsorbed on the nanostructured surface and for thiophenol in solution. $N_{S E R S}$ and $N_{\text {Raman }}$ are the numbers of thiophenol molecules on the sample surface and in the bulk illuminated by the laser, respectively. Typically, EF can be as much as $10^{4}-10^{6}$. For the number of thiophenol molecules on the sample surface, we define $N_{S E R S}$ as:

$$
N_{\text {SERS }}=N_{A} \times S_{\text {collected }} \times \frac{S_{\text {structures }}}{P^{2}} \times \sigma_{\text {Surf }}
$$

$N_{A}$ is the Avogadro's number $\left(\mathrm{mol}^{-1}\right), S_{\text {collected }}$ is the surface illumated by the laser and $S_{\text {collected }} \approx 144 \mu \mathrm{m}^{2}$ in our configuration. $S_{\text {structures }}$ is the sum of the lateral and top surfaces of the nanodisk. $\mathrm{P}$ is the period of the nanodisks, and $\sigma_{\text {Surf }}$ represents the surface coverage density of thiophenol, which is around[26] $0.54 \mathrm{nmol} / \mathrm{cm}^{2}$. In the Raman experiment (solution), the number of excited molecules $N_{\text {Raman }}$ is $4.22 \times 10^{15}$. This number is calculated from the following equation[34]: $N_{\text {Raman }}=N_{A} C V$, where $C$ is the used concentration of thiophenol (1M) and $V$ is the

scattering volume $V=7 \mathrm{~nL}$. An EF of $3.9 \times 10^{5}$ for a nanodisk array on a glass substrate with 
similar disk size and periodicity $(D=180 \mathrm{~nm}$ and $\mathrm{P}=450 \mathrm{~nm})$ was obtained in literature[35]. In our case, the presence of the gold thin film significantly increases the EF. For disks with $210 \mathrm{~nm}$ of diameter and $400 \mathrm{~nm}$ of period, we measured an EF around $2.4 \times 10^{6}$ for $633 \mathrm{~nm}, 9.7 \times 10^{6}$ for $660 \mathrm{~nm}$ and $3.8 \times 10^{7}$ for $785 \mathrm{~nm}$. EFs obtained without the gold underlayer are in good agreement with literatures and are comprised between $1.1 \times 10^{5}$ and $3.7 \times 10^{6}$ depending on the excitation wavelength and parameters of the nanostructures.

To get a better understanding of these results and to estimate the behavior of the Raman gain, it is useful to look at the link between the excitation wavelength, the Raman shift and the plasmonic resonance of this type of structure (Figure S3 : extinction profile)[36,37]. Figure 5 displays the relative SERS intensity of the characteristic peaks of thiophenol as function of the Raman shift for different excitation wavelengths. We compare these intensities to the experimental plasmonic resonance obtained through the extinction profile, for an array of nanodisks with a gold underlayer (GNGU sample). For the three excitation wavelengths, the relative SERS intensities of each peak (symbols) follow the same trend as the extinction profiles (lines a, b, c). This is in agreement with several publications [38-40], which have reported the key role of the plasmonic resonance on the SERS intensity.

Furthermore, for $210 \mathrm{~nm}$ disks with a period of $400 \mathrm{~nm}$ for the two types of sample (GNGU and $\mathrm{GN}$ ), we find $\lambda_{S P G N G U}=664 \mathrm{~nm}$ and $\lambda_{S P G N}=769 \mathrm{~nm}$ (Figure S3), where $\lambda_{S P}$ is the plasmonic resonance wavelength of each sample. We can see that $\lambda_{S P G N G U}$ is closer to the excitation wavelength of $660 \mathrm{~nm}$ than $\lambda_{S P G N}$ and this can explain part of the experimental SERS gain between GNGU and GN. 


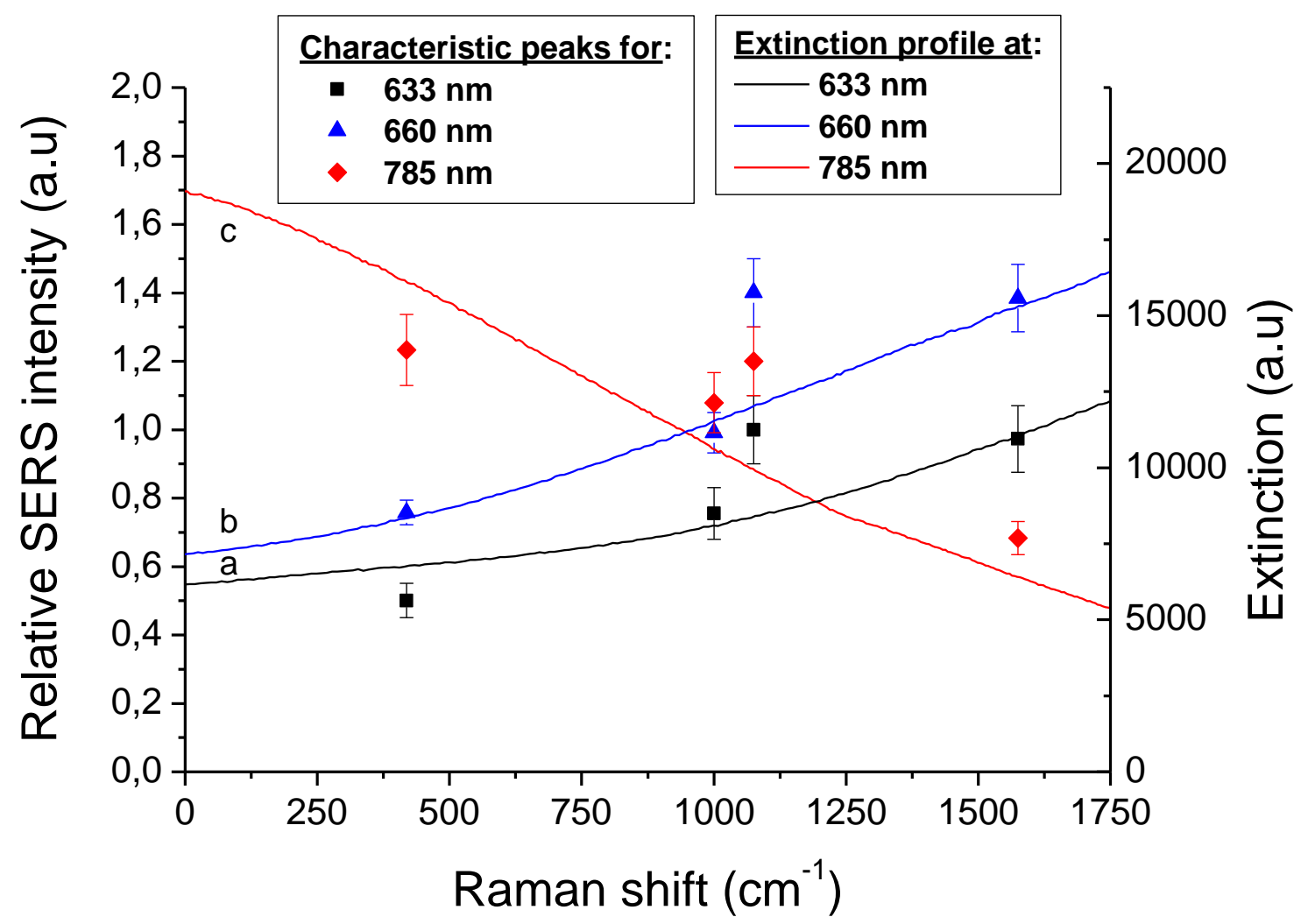

Figure 5. Comparison between the relative SERS intensities of four characteristic peaks of thiophenol $\left(419 \mathrm{~cm}^{-1}, 1000 \mathrm{~cm}^{-1}, 1075 \mathrm{~cm}^{-1}\right.$ and $\left.1575 \mathrm{~cm}^{-1}\right)$ and the extinction profiles, for different excitation wavelengths (633 $\mathrm{nm}$ (square, a), $660 \mathrm{~nm}$ (triangle, b) and $785 \mathrm{~nm}$ (diamond, c)). These measurements were made on nanodisks on a gold underlayer with $D=210 \mathrm{~nm}$ and $P=400 \mathrm{~nm}$.

In addition, coupling between surface plasmon polariton and localized surface plasmon could also provide further SERS enhancement[41]. This coupling has been already shown experimentally and demonstrated for samples with a glass substrate with a $\mathrm{SiO}_{2}$ spacer between gold nanodisks and gold film[35,42]. The possibility to have the excitation of localized and propagating surface plasmon modes can be also obtained with microhole arrays in thin Au films[43]. Finally, in 
contrary of classical structures with a metallic array on glass or Si substrates, where only the localized plasmon resonance (LSPR) can be excited and is primary contributor to SERS signal, here a uniform layer let to support the propagating surface plasmon (PSP) resonance. Due to the large numerical aperture of our setup (0.9), such coupling between the different modes is possible and could provide a better SERS intensity.

Finally, some of the EFs obtained with GNGU and GN samples for arrays of nanodisks and lines are shown in Figure 6. We observe that the overall enhancement factor of nanodisks is higher than for lines, showing the difference between a 1D and a 2D lattice and in agreement with the higher confinement of electromagnetic field in nanodisks. Note that, EF are normalized by the nanostructure surface. 


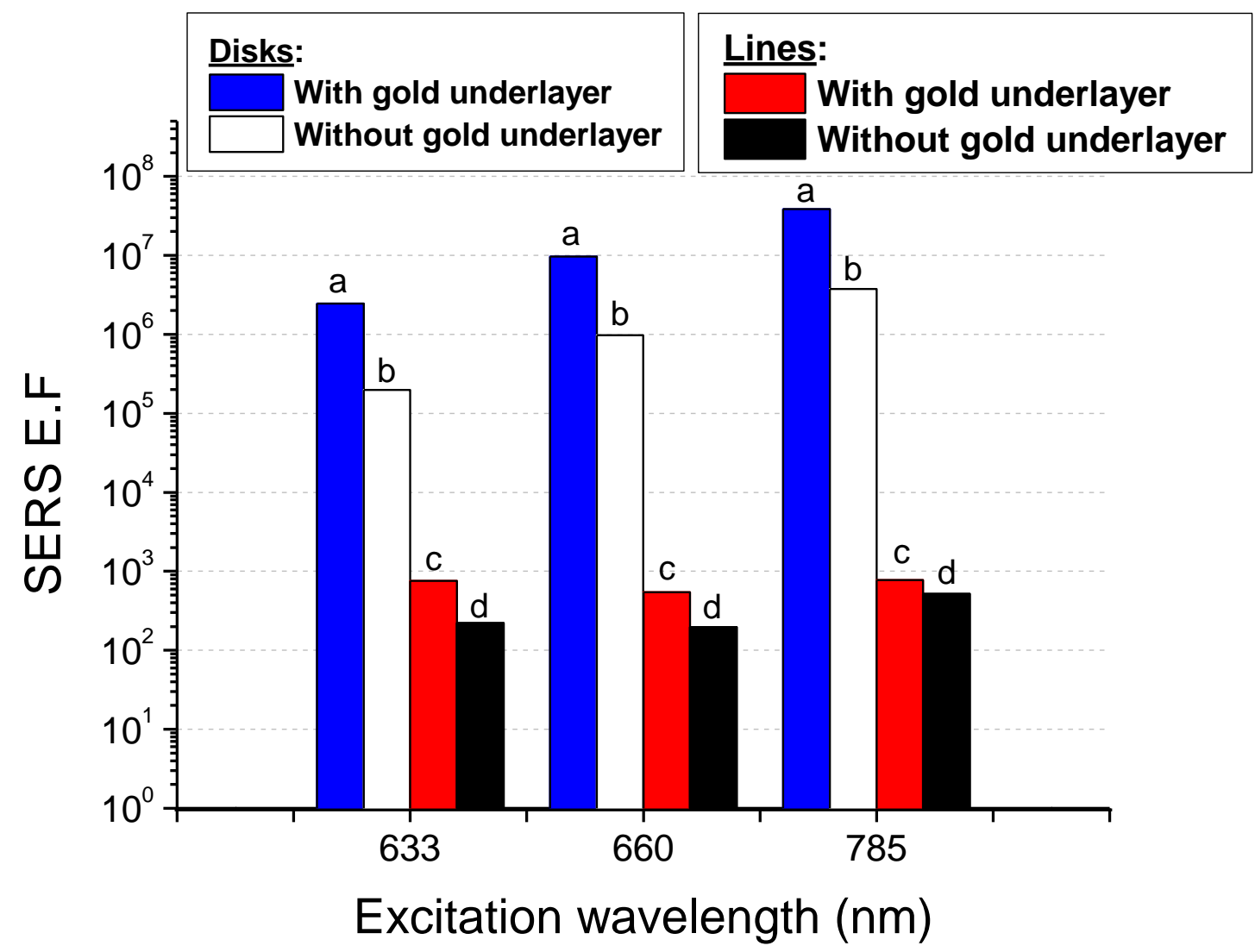

Figure 6. Evolution of the SERS Enhancement Factor, at $1575 \mathrm{~cm}^{-1}$, for three excitation wavelengths. (a), (b), (c) and (d) are, respectively, EF for gold nanodisks ( $D=210 \mathrm{~nm}, P=400$ nm) of GNGU, GN, gold lines ( $W=110 \mathrm{~nm}, P=400 \mathrm{~nm}$ ) of $G N G U$ and $G N$.

EFs increase from $633 \mathrm{~nm}$ to $785 \mathrm{~nm}$ by a factor around 10, which is in good agreement with previous results showing the importance of the excitation wavelength as function of the diameter ${ }^{[44]}$ for disks. A further optimization of the optical response could be done by replacing the titanium adhesive layer by 3-mercaptopropyl-trimethoxysilane (MPTMS) in order to reduce the optical damping ${ }^{[45]}$ where a gain around 10 is obtain in replacement of the chrome (also used as adhesive 
layer for gold on glass) by MPTMS, by increase the thickness of gold layer or by reducing the gap between nanostructures to obtain zones of stronger EM fields[46].

\section{CONCLUSION}

In summary, in the context of plasmonic substrates, placing gold underlayer film under regular disk or line arrays has allowed demonstrating a significant improvement of the SERS effect, which can be controlled by varying the diameter/width or the periodicity of nanostructures. Furthermore the reproducibility as well as the homogeneity of the nanostructure realization is improved by adding such gold underlayer, which is also of great interest for industrial applications. Enhancement factors, EFs, close to $6 \times 10^{7}$ were measured with thiophenol. Independently of the geometrical parameters (110 and $210 \mathrm{~nm}$ disks with periodicities from $200 \mathrm{~nm}$ to $400 \mathrm{~nm}$ and lines of $110 \mathrm{~nm}$ of width and periods of 400 and $500 \mathrm{~nm}$ ) and the excitation wavelength (633, 660 or $785 \mathrm{~nm}$ ), a gain of one order of magnitude is observed for Gold Nanostructures on Gold Underlayer substrates in comparison to classical Gold Nanostructures substrates. This approach could be generalized to other nanostructures (pyramids, nanorings) to improve the performance of biosensors based on the exploitation of the optical properties of the nanostructures such as SPR sensors or other plasmonic enhanced spectroscopies.

\section{AUTHOR INFORMATION}

Corresponding Author

*E-mail: jean-francois.bryche@u-psud.fr 


\section{ACKNOWLEDGEMENTS.}

The authors acknowledge ANR P2N (ANR-12-NANO-0016) and the support of the French Government for partial funding of the project in which this work takes place. This work was partly supported by the French RENATECH network. IOGS/CNRS is also part of the European Network of Excellence in BioPhotonics, Photonics for Life, P4L.

\section{REFERENCES}

1. Raman CV (1928) A new radiation. Indian Journal of physics 2:387-398

2. Fleischmann M, Hendra P, McQuillan A (1974) Raman spectra of pyridine adsorbed at a silver electrode. Chemical Physics Letters 26 (2):163-166

3. Le Ru EC, Etchegoin PG (2012) Single-Molecule Surface-Enhanced Raman Spectroscopy. Annual Review of Physical Chemistry 63 (1):65-87. doi:doi:10.1146/annurev-physchem-032511-143757

4. Sharma B, Frontiera RR, Henry A-I, Ringe E, Van Duyne RP (2012) SERS: Materials, applications, and the future. Materials Today 15 (1-2):16-25. doi:http://dx.doi.org/10.1016/S1369-7021(12)70017-2

5. Guillot N, de la Chapelle ML (2012) Lithographied nanostructures as nanosensors. NANOP 6 (1):064506-064501-064506-064528. doi:10.1117/1.JNP.6.064506

6. Vo-Dinh T, Wang H-N, Scaffidi J (2010) Plasmonic nanoprobes for SERS biosensing and bioimaging. Journal of Biophotonics 3 (1-2):89-102. doi:10.1002/jbio.200910015

7. Tian ZQ, Ren B, Wu DY (2002) Surface-enhanced Raman scattering: From noble to transition metals and from rough surfaces to ordered nanostructures. J Phys Chem B 106 (37):9463-9483. doi:10.1021/jp0257449

8. Baia M, Baia L, Astilean S, Popp J (2006) Surface-enhanced Raman scattering efficiency of truncated tetrahedral $\mathrm{Ag}$ nanoparticle arrays mediated by electromagnetic couplings. Applied Physics Letters 88 (14):143121. doi:doi:http://dx.doi.org/10.1063/1.2193778

9. Yuan H, Fales AM, Khoury CG, Liu J, Vo-Dinh T (2013) Spectral characterization and intracellular detection of Surface-Enhanced Raman Scattering (SERS)-encoded plasmonic gold nanostars. Journal of Raman Spectroscopy 44 (2):234-239. doi:10.1002/jrs.4172

10. Vo-Dinh T, Dhawan A, Norton SJ, Khoury CG, Wang H-N, Misra V, Gerhold MD (2010) Plasmonic Nanoparticles and Nanowires: Design, Fabrication and Application in Sensing. The Journal of Physical Chemistry C 114 (16):7480-7488. doi:10.1021/jp911355q

11. Guillot N, de la Chapelle ML (2012) The electromagnetic effect in surface enhanced Raman scattering: Enhancement optimization using precisely controlled nanostructures. Journal of Quantitative Spectroscopy and Radiative Transfer 113 (18):2321-2333. doi:http://dx.doi.org/10.1016/j.jqsrt.2012.04.025

12. Brown RJC, Milton MJT (2008) Nanostructures and nanostructured substrates for surface — enhanced Raman scattering (SERS). Journal of Raman Spectroscopy 39 (10):1313-1326. doi:10.1002/jrs.2030

13. Cialla D, Marz A, Bohme R, Theil F, Weber K, Schmitt M, Popp J (2012) Surface-enhanced Raman spectroscopy (SERS): progress and trends. Anal Bioanal Chem 403 (1):27-54. doi:10.1007/s00216-011$5631-x$ 
14. Fan M, Andrade GFS, Brolo AG (2011) A review on the fabrication of substrates for surface enhanced Raman spectroscopy and their applications in analytical chemistry. Analytica Chimica Acta 693 (1-2):725. doi:http://dx.doi.org/10.1016/j.aca.2011.03.002

15. Yu QM, Braswell S, Christin B, Xu JJ, Wallace PM, Gong H, Kaminsky D (2010) Surface-enhanced Raman scattering on gold quasi-3D nanostructure and 2D nanohole arrays. Nanotechnology 21 (35):9. doi:10.1088/0957-4484/21/35/355301

16. Yue WS, Yang Y, Wang ZH, Han JG, Syed A, Chen LQ, Wong K, Wang XB (2012) Improved surfaceenhanced Raman scattering on arrays of gold quasi-3D nanoholes. J Phys D-Appl Phys 45 (42):7. doi:10.1088/0022-3727/45/42/425401

17. Yu Q, Guan P, Qin D, Golden G, Wallace PM (2008) Inverted Size-Dependence of Surface-Enhanced Raman Scattering on Gold Nanohole and Nanodisk Arrays. Nano Letters 8 (7):1923-1928. doi:10.1021/n10806163

18. Lin YY, Liao JD, Ju YH, Chang CW, Shiau AL (2011) Focused ion beam-fabricated Au micro/nanostructures used as a surface enhanced Raman scattering-active substrate for trace detection of molecules and influenza virus. Nanotechnology 22 (18):8. doi:10.1088/0957-4484/22/18/185308

19. Hamouda F, Sahaf H, Held S, Barbillon G, Gogol P, Moyen E, Aassime A, Moreau J, Canva M, Lourtioz JM, Hanbucken M, Bartenlian B (2011) Large area nanopatterning by combined anodic aluminum oxide and soft UV-NIL technologies for applications in biology. Microelectron Eng 88 (8):2444-2446. doi:10.1016/j.mee.2011.02.013

20. Lee SY, Jeon HC, Yang SM (2012) Unconventional methods for fabricating nanostructures toward highfidelity sensors. J Mater Chem 22 (13):5900-5913. doi:10.1039/c2jm16568f

21. Barbillon G, Hamouda F, Held S, Gogol P, Bartenlian B (2010) Gold nanoparticles by soft UV nanoimprint lithography coupled to a lift-off process for plasmonic sensing of antibodies. Microelectron Eng 87 (5-8):1001-1004. doi:http://dx.doi.org/10.1016/j.mee.2009.11.114

22. Masson J-F, Gibson KF, Provencher-Girard A (2010) Surface-Enhanced Raman Spectroscopy Amplification with Film over Etched Nanospheres. The Journal of Physical Chemistry C 114 (51):2240622412. doi:10.1021/jp106450y

23. Fang C, Frontiera RR, Tran R, Mathies RA (2009) Mapping GFP structure evolution during proton $\begin{array}{llllll}\text { transfer with femtosecond Raman spectroscopy. Nature } 462 & \text { (7270):200-204. }\end{array}$ doi:http://www.nature.com/nature/journal/v462/n7270/suppinfo/nature08527_S1.html

24. Klingsporn JM, Sonntag MD, Seideman T, Van Duyne RP (2014) Tip-Enhanced Raman Spectroscopy with Picosecond Pulses. J Phys Chem Lett 5 (1):106-110. doi:10.1021/jz4024404

25. Barchiesi D, Kessentini S, Guillot N, de la Chapelle ML, Grosges T (2013) Localized surface plasmon resonance in arrays of nano-gold cylinders: inverse problem and propagation of uncertainties. Opt Express 21 (2):2245-2262

26. Caldwell JD, Glembocki O, Bezares FJ, Bassim ND, Rendell RW, Feygelson M, Ukaegbu M, Kasica R, Shirey L, Hosten C (2011) Plasmonic Nanopillar Arrays for Large-Area, High-Enhancement SurfaceEnhanced Raman Scattering Sensors. ACS Nano 5 (5):4046-4055. doi:10.1021/nn200636t

27. Hohenau A, Krenn JR, Garcia-Vidal FJ, Rodrigo SG, Martin-Moreno L, Beermann J, Bozhevolnyi SI (2007) Spectroscopy and nonlinear microscopy of gold nanoparticle arrays on gold films. Physical Review B 75 (8):085104

28. Hohenau A, Krenn JR, Beermann J, Bozhevolnyi SI, Rodrigo SG, Martin-Moreno L, Garcia-Vidal F (2006) Spectroscopy and nonlinear microscopy of Au nanoparticle arrays: Experiment and theory. Physical Review B 73 (15): 155404

29. Hohenau A, Krenn JR, Garcia-Vidal FJ, Rodrigo SG, Martin-Moreno L, Beermann J, Bozhevolnyi SI (2007) Comparison of finite-difference time-domain simulations and experiments on the optical properties of gold nanoparticle arrays on gold film. Journal of Optics A: Pure and Applied Optics 9 (9):S366 
30. Wang Y, Abb M, Boden SA, Aizpurua J, de Groot CH, Muskens OL (2013) Ultrafast Nonlinear Control of Progressively Loaded, Single Plasmonic Nanoantennas Fabricated Using Helium Ion Milling. Nano Letters 13 (11):5647-5653. doi:10.1021/n1403316z

31. Iriarte GF, Rodriguez-Madrid JG, Calle F (2012) Fabrication of sub-100 nm IDT SAW devices on insulating, semiconducting and conductive substrates. J Mater Process Technol 212 (3):707-712. doi:10.1016/j.jmatprotec.2011.08.007

32. Aassime A, Hamouda F, Richardt I, Bayle F, Pillard V, Lecoeur P, Aubert P, Bouchier D (2013) Anticharging process for electron beam observation and lithography. Microelectron Eng 110:320-323. doi:10.1016/j.mee.2013.02.036

33. Zhou Q, Liu Y, He Y, Zhang Z, Zhao Y (2010) The effect of underlayer thin films on the surfaceenhanced Raman scattering response of Ag nanorod substrates. Applied Physics Letters 97 (12):121902. doi:doi:http://dx.doi.org/10.1063/1.3489973

34. Cottat M, Lidgi-Guigui N, Tijunelyte I, Barbillon G, Hamouda F, Gogol P, Aassime A, Lourtioz J-M, Bartenlian B, de la Chapelle M (2014) Soft UV nanoimprint lithography-designed highly sensitive substrates for SERS detection. Nanoscale Research Letters 9 (1):623

35. Chu Y, Banaee MG, Crozier KB (2010) Double-Resonance Plasmon Substrates for Surface-Enhanced Raman Scattering with Enhancement at Excitation and Stokes Frequencies. ACS Nano 4 (5):2804-2810. doi:10.1021/nn901826q

36. Mandal P, Ramakrishna SA (2011) Dependence of surface enhanced Raman scattering on the plasmonic template periodicity. Opt Lett 36 (18):3705-3707. doi:10.1364/OL.36.003705

37. Mandal P, Nandi A, Ramakrishna SA (2012) Propagating surface plasmon resonances in twodimensional patterned gold-grating templates and surface enhanced Raman scattering. Journal of Applied Physics 112 (4):044314. doi:doi:http://dx.doi.org/10.1063/1.4748180

38. Willets KA, Van Duyne RP (2007) Localized surface plasmon resonance spectroscopy and sensing. Annu Rev Phys Chem 58:267-297

39. Aroca R (2006) Surface Enhanced Vibrational Spectroscopy.

40. Le Ru EC, Grand J, Félidj N, Aubard J, Lévi G, Hohenau A, Krenn JR, Blackie E, Etchegoin PG (2008) Experimental Verification of the SERS Electromagnetic Model beyond the $|\mathrm{E}| 4$ Approximation: Polarization Effects. The Journal of Physical Chemistry C 112 (22):8117-8121. doi:10.1021/jp802219c

41. Sarkar M, Besbes M, Moreau J, Bryche J-F, Olivéro A, Barbillon G, Coutrot A-L, Bartenlian B, Canva M (2015) Hybrid Plasmonic Mode by Resonant Coupling of Localized Plasmons to Propagating Plasmons in a Kretschmann Configuration. ACS Photonics 2 (2):237-245. doi:10.1021/ph500351b

42. Chu Y, Crozier KB (2009) Experimental study of the interaction between localized and propagating surface plasmons. Opt Lett 34 (3):244-246. doi:10.1364/OL.34.000244

43. Live LS, Dhawan A, Gibson KF, Poirier-Richard H-P, Graham D, Canva M, Vo-Dinh T, Masson J-F (2012) Angle-dependent resonance of localized and propagating surface plasmons in microhole arrays for enhanced biosensing. Anal Bioanal Chem 404 (10):2859-2868

44. Guillot N, Shen H, Fremaux B, Peron O, Rinnert E, Toury T, de la Chapelle ML (2010) Surface enhanced Raman scattering optimization of gold nanocylinder arrays: Influence of the localized surface plasmon resonance and excitation wavelength. Applied Physics Letters 97 (2):23113. doi:Artn 023113

Doi 10.1063/1.3462068

45. Shen H, Guillot N, Rouxel J, Lamy de la Chapelle M, Toury T (2012) Optimized plasmonic nanostructures for improved sensing activities. Opt Express 20 (19):21278-21290. doi:10.1364/OE.20.021278 
46. Bryche J-F, Gillibert R, Barbillon G, Sarkar M, Coutrot A-L, Hamouda F, Aassime A, Moreau J, Lamy de la Chapelle M, Bartenlian B, Canva M (2015) Density effect of gold nanodisks on the SERS intensity for a highly sensitive detection of chemical molecules. J Mater Sci:1-7. doi:10.1007/s10853-015-9203-x 


\section{SUPPLEMENTARY DATA}

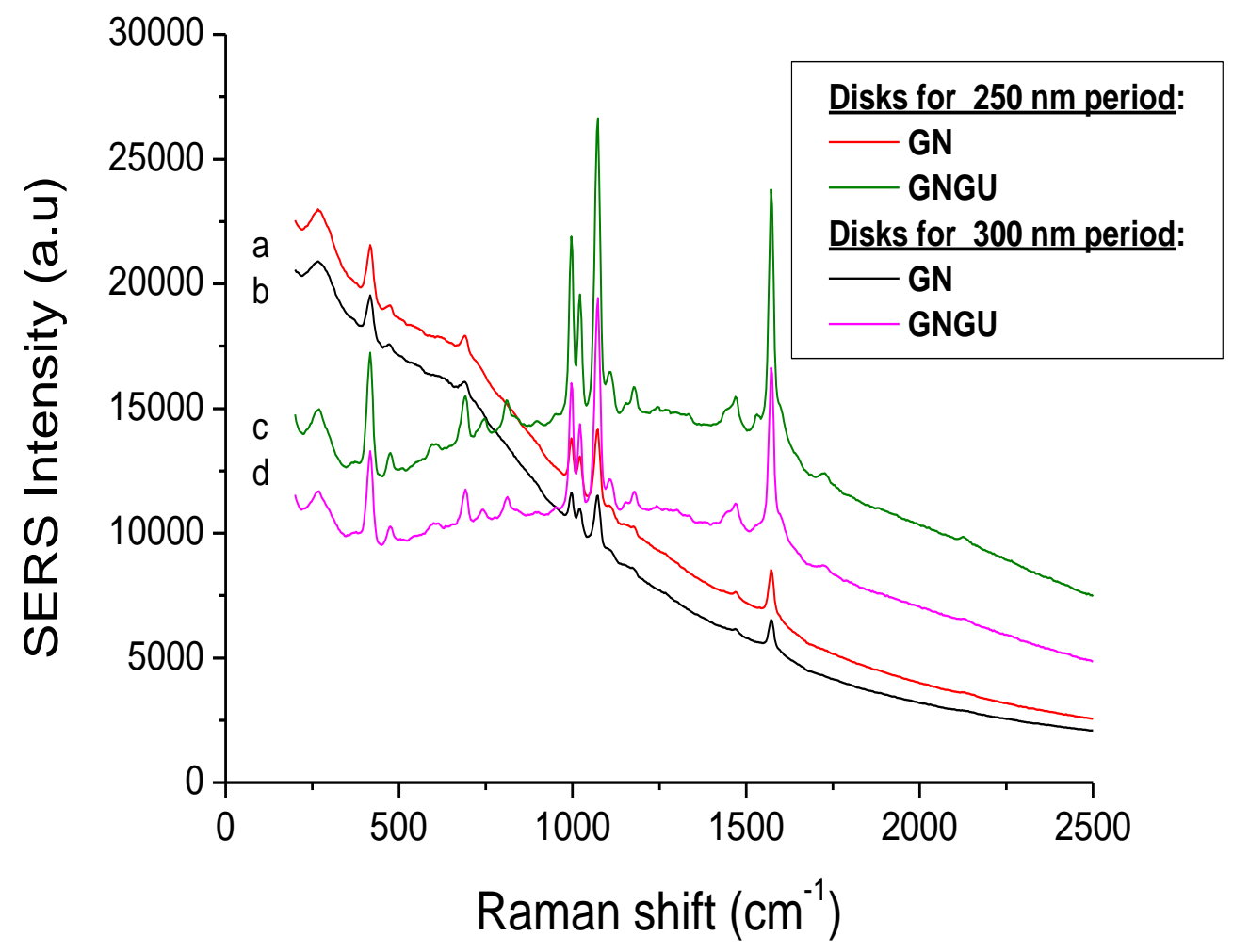

Figure S1. SERS intensity versus Raman shift for an array of nanodisks with a diameter of $110 \mathrm{~nm}$ and a period of $250 \mathrm{~nm}$ on glass (GN) (a) and on gold (GNGU) (c), with a period of $300 \mathrm{~nm}$ on glass (GN) (b) and on gold (GNGU) (d). The excitation wavelength is $660 \mathrm{~nm}$. 
a)

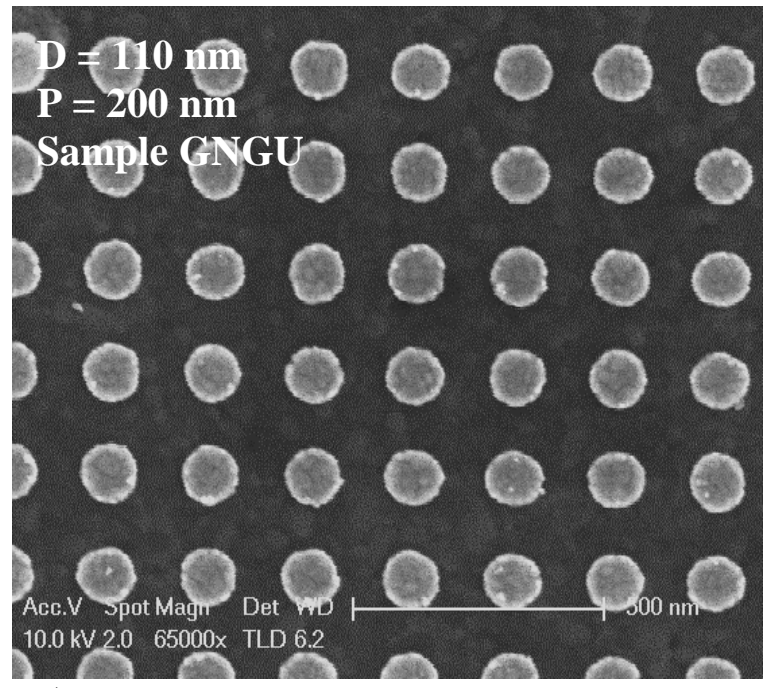

c)

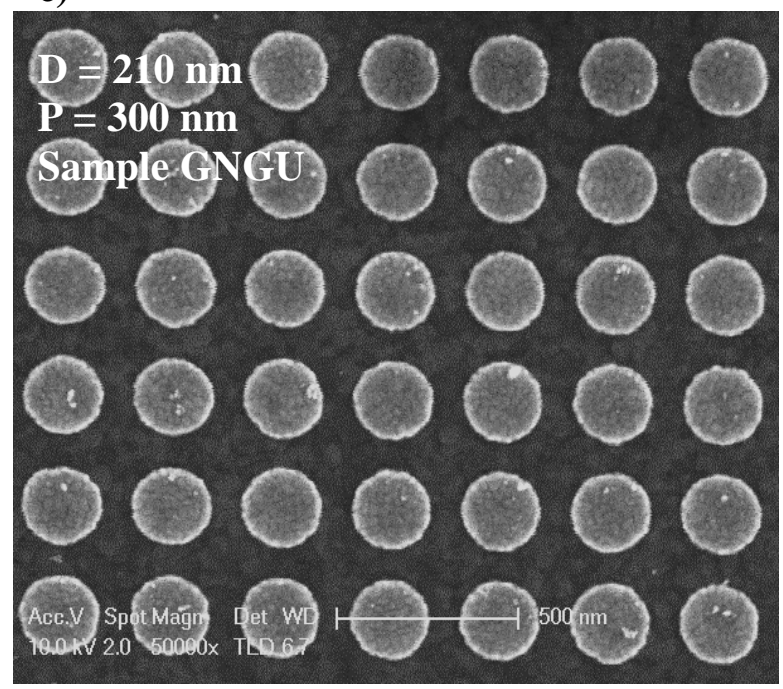

b)

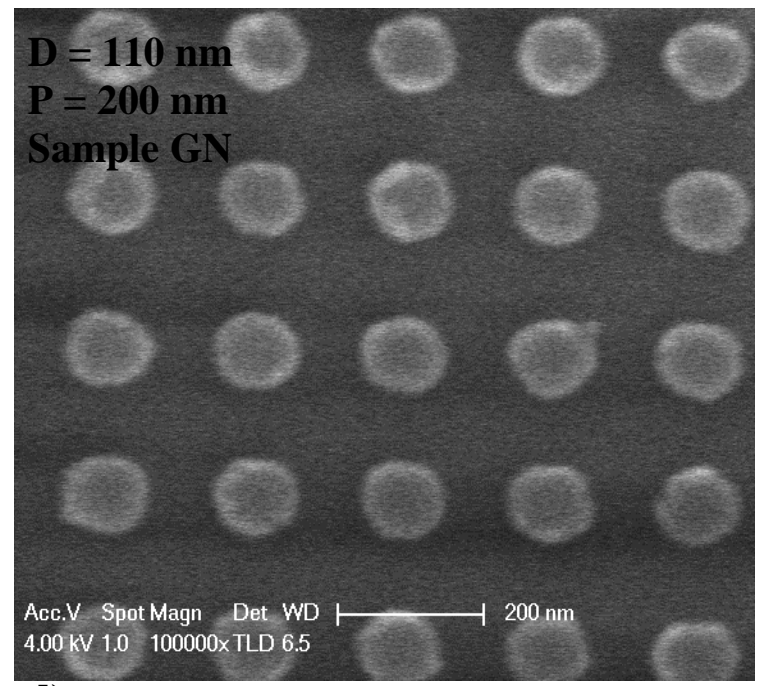

d)

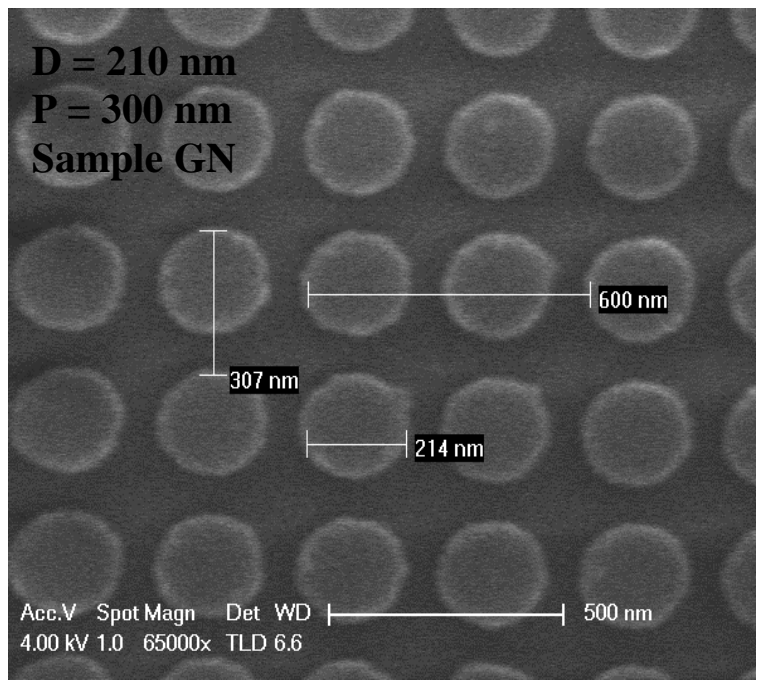

Figure S2. SEM pictures of gold disks $(a, c)$ for $G N G U$ and $(b, d)$ for $G N$. 


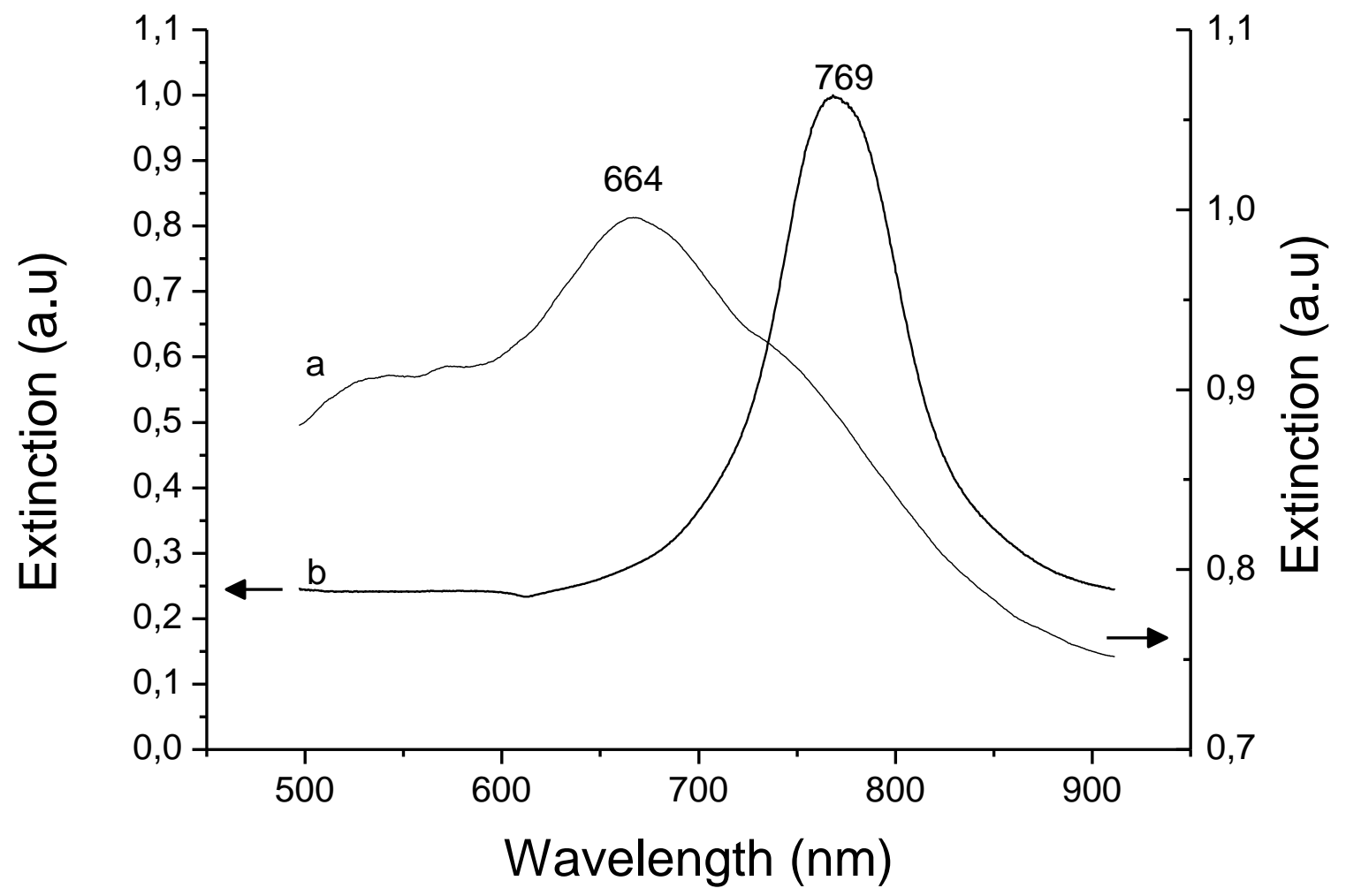

Figure S3. Extinction spectra of nanodisks $(D=210 \mathrm{~nm}, P=400 \mathrm{~nm})$ for: (a) GNGU sample and (b) for GN sample. 